\title{
Corpo e infecções sexualmente transmissíveis: análise dos conteúdos nos livros didáticos de ciências e biologia
}

\author{
Myller Gomes Machado \\ Graduado (Licenciatura) em Ciências Biológicas pela Universidade Federal da Paraíba (UFPB); \\ Mestre em Desenvolvimento e Meio Ambiente (PRODEMA) pela Universidade Federal da Paraíba (UFPB); \\ Doutorando no Programa de Pós-Graduação em Educação (Linha Processos de Ensino-Aprendizagem) pela \\ Universidade Federal da Paraíba (UFPA). \\ $凶$ myller-20@hotmail.com
}

\section{Francisco José Pegado Abílio}

Bacharel em Ciências Biológicas pela Universidade Federal da Paraíba (UFPB);

Licenciado em Ciências Biológicas pela Universidade Federal da Paraíba (UFPB);

Mestre em Ciências Biológicas (Zoologia) pela Universidade Federal da Paraíba (UFPB);

Doutor em Ciências (Ecologia e Recursos Naturais) pela Universidade Federal de São Carlos (UFCar); Professor associado IV do Departamento de Metodologia da Educação da Universidade Federal da Paraíba (UFPB).

\section{Divaniella de Oliveira Lacerda}

Licenciada em Ciências Biológicas pela Universidade Federal da Paraíba (UFPB); Bacharelanda do Curso de Ciências Biológicas pela Universidade Federal da Paraíba (UFPB); Mestranda do Programa de Pós Graduação em Educação (PPGE) pela Universidade Federal da Paraíba (UFPB).

\section{Resumo:}

Os Livros Didáticos (LD), de uma maneira geral, têm sido o principal recurso didático utilizado nas salas de aula na educação básica, fazendo-se necessária a realização de análises criteriosas desse material. Assim o presente estudo objetivou analisar, como os conteúdos referentes à Corpo e Infecções Sexualmente Transmissíveis (IST) são discutidos nos LD de Ciências e Biologia, dos níveis Fundamental e Médio, respectivamente, aprovados pelo Programa Nacional do Livro Didático. Este estudo caracterizou-se como uma pesquisa de cunho Qualitativo, utilizando-se elementos da Análise Conteúdo, Pesquisa Documental e Bibliográfica. Foram categorizados e analisados 39 LD de Biologia e 22 LD de Ciências publicados no período de 2002 a 2012. Como Resultados, observou-se que na categoria "Corpo", a subconstituinte "Ciclo Geral", obteve maior frequência, já a subconstituinte com menor frequência foi "Aborto". Pertinente à categoria IST, a subcontituinte "Sífilis" obteve maior frequência absoluta nos LD de Biologia, já nos LD de Ciências foi "AIDS". Foram perceptíveis, durante a análise, equívocos e informações incompletas acerca de algumas temáticas, como no processo de fecundação (sobre a não entrada do flagelo do espermatozoide no citoplasma do óvulo) e de algumas IST, a exemplo de quais tipos de hepatites são transmitidas no ato sexual. Portanto, pode-se afirmar que o LD não deve ser o único recurso utilizado pelo professor na sala de aula no processo de ensino-aprendizagem.

Palavras-chave: Educação, Livros Didáticos, Análise de Conteúdo, Corpo, Infecções Sexualmente Transmissíveis. 
Corpo e infecções sexualmente transmissíveis: análise

dos conteúdos nos livros didáticos de ciências e biologia

\title{
Body and sexually transmitted infections: analysis of contents in the didactic books of sciences and biology
}

\begin{abstract}
:
The Didactic Books (DB), in general, have been the main didactic resource used in classrooms in basic education, making it necessary to carry out careful analysis of this material. Thus the present study aimed to critically analyze how the contents referring to the Body and Sexually Transmitted Infections (STI) are discussed in the DB of Science and Biology, at the Fundamental and Middle levels, respectively, approved by the National Textbook Program. This study was characterized as a Qualitative research, using elements of Content Analysis, Documentary and Bibliographic Research. We classified and analyzed $39 \mathrm{DB}$ of Biology and 22 DB of Sciences published in the period from 2002 to 2012. As results, it was observed that in the category "Body", the sub-constituent "General Cycle", obtained more frequency, since the subconstituent with less frequency was "Abortion". Relevant to the STI category, the sub-constituent "Syphilis" obtained higher absolute frequency in the DB of Biology, since in the DB of Sciences it was "AIDS". During the analysis, misunderstandings and incomplete information about some topics, such as the fertilization process (on the spermatozoon's failure to enter the egg's cytoplasm) and some STI, such as which types of hepatitis are transmitted in the sexual act. Therefore, it can be stated that the textbook should not be the only resource used by the teacher in the classroom in the teaching-learning process.

Keywords: Education, Didatic books, Content Analysis, Body, Sexually Transmitted Infections.
\end{abstract}

\section{Cuerpo e infecciones sexualmente transmisibles: análisis de los contenidos en los libros didácticos de ciencias y biología}

\section{Resumen:}

Los Libros Didácticos (LD), de una manera general, han sido el principal recurso didáctico utilizado en las aulas en la educación básica, haciéndose necesaria la realización de análisis juiciosos de ese material. El presente estudio objetivó analizar, como los contenidos referentes al Cuerpo e Infecciones Sexualmente Transmisibles (IST) son discutidos en los LD de Ciencias y Biología, de los niveles Fundamental y Medio, respectivamente, aprobados por el Programa Nacional del Libro Didáctico. Este estudio se caracterizó como una investigación de cuño Cualitativo, utilizando elementos del Análisis Contenido, Investigación Documental y Bibliográfica. En la categoría "Cuerpo", la subconstituyente "Ciclo General", obtuvo una mayor frecuencia, ya la subconstitución con menor número de niños y niñas, en el período de 2002 a 2012. Como resultados, se observó que en la categoría "Cuerpo" la frecuencia fue "Aborto". En cuanto a la categoría IST, la subcon- secundaria "Sífilis" obtuvo mayor frecuencia absoluta en los LD de Biología, ya en los LD de Ciencias fue "SIDA". En el análisis, los equívocos e informaciones incompletas sobre algunas temáticas, como en el proceso de fecundación (sobre la no entrada del flagelo del espermatozoide en el citoplasma del óvulo) y de algunas IST, a ejemplo de qué tipos de hepatitis se transmiten en el transcurso del análisis, el acto sexual. Por lo tanto, se puede afirmar que el LD no debe ser el único recurso utilizado por el profesor en el aula en el proceso de enseñanza-aprendizaje.

Palabras clave: Educación, Libros didaticos, Análisis de contenido, Cuerpo, Infecciones de transmisión sexual.

\section{INTRODUÇÃO}

No estágio atual do ensino brasileiro, a configuração do Currículo Escolar dos ensinos fundamental e médio deve ser objeto de intensos debates, para que a escola possa 
desempenhar adequadamente seu papel na formação de cidadãos. Isso não é diferente nas Ciências Biológicas, que na Educação Básica, pode ser uma das disciplinas mais relevantes ou uma das mais insignificantes e pouco atraentes, isso depende, principalmente, do que é ensinado e quais os recursos e instrumentos utilizado neste processo (KRASILCHIK, 2004).

Assim, um dos principais Recursos Didáticos utilizados pelos professores e que pode ser ponto crucial na significância das Ciências Biológicas por parte dos alunos é o Livro Didático (LD), e por possuir consideráveis limitações, é de grande importância à reflexão quanto às abordagens dos conteúdos propostos no currículo escolar. Neste contexto, evidencia-se temas como o Corpo e as Infecções Sexualmente Transmissíveis (IST) ${ }^{1}$, que estão presentes nos LD e que faz-se necessário reflexões, problematizações e aprofundamentos teóricos e metodológicos.

A temática Saúde, de acordo com Brasil (2001), apenas em 1971 foi formalmente introduzida no currículo escolar brasileiro, sob a designação genérica de "Programa de Saúde", e tinha como objetivo de "levar a criança e o adolescente ao desenvolvimento de hábitos saudáveis quanto à higiene pessoal, alimentação, prática desportiva, ao trabalho e ao lazer, permitindo-lhes a sua utilização imediata no sentido de preservar a saúde pessoal e a dos outros" (Lei de 1971, sob o n 5.692).

Já a Orientação Sexual, torna-se uma temática transversal, a partir dos Parâmetros Curriculares Nacionais (PCN), no final da década 1990. Na qual é destacado principalmente o corpo e suas dimensões, as relações de gênero e as IST (BRASIL, 2001). Sendo proposto que os professores trabalhassem este tema englobando não só as questões biológicas, mas também psicológicas e sociais. Entretanto, a prática ocorre lentamente, e atualmente ainda observa-se certo desconforto em falar destas assuntos, como é o caso da Sexualidade, sendo comum encontrar docentes que ainda consideram que o assunto deveria ser apenas abordada por especialistas (RIBEIRO, 2004). Além disso, os LD e paradidáticos, muitas vezes, são insuficientes e/ou contém erros constantes, o que dificulta, mais ainda, o processo de ensino-aprendizagem.

Todavia, estamos em uma época caracterizada como sendo recheadas de transformações nas formas da sexualidade. Desta forma, as escolas têm que abandonar o

\footnotetext{
${ }^{1}$ Utilização da nomenclatura IST, substituindo DST, a partir do Decreto no 8.901/2016 publicada no Diário Oficial da União em 11.11.2016, Seção I, páginas 03 a 17. Disponível em: http://www.planalto.gov.br/ccivil_03/_ato2015-2018/2016/decreto/D8901.htm Acesso em: 09 set. 2018.
} 
silêncio e o segredo e incorporar essas temáticas no currículo escolar e nas discussões no contexto da sala de aula.

\section{Livros Didáticos, Ciências Biológicas e a Sexualidade}

Os LD, de uma maneira geral, têm sido o principal recurso didático utilizado nas salas de aula na educação básica, fazendo-se necessária a realização de análises criteriosas desse material com intuito de não só reduzir os problemas relacionados aos conteúdos conceituais, mas também procedimentais e atitudinais. Essa assertiva é corroborada com os Parâmetros Curriculares Nacionais - Ensino Médio (PCNEM) (BRASIL, 2000) quando menciona que o LD deve ser utilizado como ferramenta auxiliar, de forma que no âmbito escolar, a autonomia deve refletir o compromisso da proposta pedagógica com a aprendizagem dos alunos pelo uso equânime dos recursos didáticos.

Para isso, a adequação pedagógica dos LD deve ser analisada a partir das seguintes referências básicas: adaptação dos conteúdos a realidade dos educandos; que as atividades propostas sejam instigantes, busquem problematizar a realidade; proposição de projetos de investigação de atividades em grupo, enquetes, dramatizações, exposições de trabalho; valorização da experiência de vida do aluno, etc. (BIZZO, 1996; BIZZO, 2002).

Neste sentido, os livros sobre os conhecimentos biológicos estão diretamente interligados com as nossas vidas, dado o avanço dessa ciência em alguns de seus domínios. A linguagem científica tem crescentemente integrado nosso vocabulário; termos como DNA, cromossomo, genoma, clonagem, efeito estufa, transgênico, a reprodução, a evolução da vida e da vida humana em toda sua diversidade de organização e interação não são completamente desconhecidos dos indivíduos minimamente informados. (BRASIL, 2002).

Admite-se que a formação biológica contribua para que cada indivíduo seja capaz de compreender e aprofundar as explicações atualizadas de processos e de conceitos biológicos, a importância da ciência e da tecnologia na vida moderna, enfim, o interesse pelo mundo dos seres vivos. Esses conhecimentos devem contribuir, também, para que o cidadão seja capaz de usar o que aprendeu ao tomar decisões de interesse individual e coletivo, no contexto de um quadro ético de responsabilidade e respeito que leve em conta o papel do ser humano enquanto constituinte da biosfera e ser político-social (KRASILCHIK, 2004). 
Neste contexto um dos temas de maior relevância que é abordado nos LD de Ciências e Biologia é a Sexualidade, com ênfase no Corpo e nas IST. Sendo de extrema importância que os docentes que discutem a(s) temática(s) estejam sempre em processo de formação continuada, já que estar-se tratando de algo com grande relevância na formação dos seres humanos e assim da sociedade.

Sobre sexualidade, Weeks (2007, p. 43), vai defini-la como "uma descrição geral para a série de crenças, comportamentos, relações e identidades socialmente construídas e historicamente modeladas que se relacionam com que Michel Foucault denominou 'o corpo e seus prazeres".

A sexualidade, além de nos proporcionar o contato com o outro e a reflexão de experiências individuais e coletivas, ela relaciona-se como um pressuposto valioso para a vivência política do sujeito na sociedade (COSTA, 2009). Foucault (1997) explicita que a Sexualidade se constrói não apenas no biológico, mas principalmente no imaginário: a sexualidade se coloca não apenas no palpável, mas sim no discurso que sustenta o palpável, na ideologia subjacente aos padrões de 'normalidade' imposto na convivência social.

A sexualidade é a dimensão que pode proporcionar maior prazer para os sujeitos e, também, a que pode causar o maior número de preocupações, sobretudo nos setores da sociedade onde estão em formação as crianças e os jovens: a família e a escola. No âmbito formal, o maior desafio é ajudá-los a expandirem seu potencial e não impedirem o desenvolvimento natural, que geralmente ocorre, em direção ao bem-estar, ao prazer e a felicidade.

Sobre o Corpo, Louro (2000) afirma que:

as muitas formas de fazer-se mulher ou homem, as várias possibilidades de viver prazeres e desejos corporais são sempre sugeridas, anunciadas, promovidas socialmente (e hoje possivelmente de formas mais explícitas do que antes). Elas são também, renovadamente, reguladas, condenadas ou negadas. (p. 04).

Corroborando, Corrêa (2013, p. 5) menciona que "o significado do corpo vai além do seu sentido biológico, tendo um sentido social e político, sendo que as significações que lhe atribuímos, bem como à sexualidade, são socialmente e historicamente organizados", "sendo sustentados por uma variedade de linguagens que buscam nos dizer o que o sexo é, o 
que deve ser e o que ele pode ser (WEEKS, 2007, p.43).", ou seja, muito mais que o depositário de vísceras, tecidos e plexos, de características genotípicas e fenotípicas, que definem determinado sujeito, o corpo vai se constituir como o conjunto de significações, ideias e imagens, matizadas e derivadas das ideologias e instituições de uma época determinada, que o corporificam e lhe conferem sentido (CORRÊA, 2013).

Assim a temática da Sexualidade, com ênfase no Corpo e nas IST, surge como uma possibilidade fecunda de engajamento de professores e alunos, nas quais a problematização tem sido facilmente atingida, por envolver direta ou indiretamente, questões vitais.

Portanto, esta pesquisa se propôs a analisar como os conteúdos referentes à Corpo e as IST são discutidos nos livros didáticos de Ciências e Biologia, dos níveis Fundamental e Médio, respectivamente, aprovados pelo Programa Nacional do Livro Didático (PNLD) no período de 2002 a 2012.

\section{METODOLOGIA}

O trabalho caracterizou-se como uma pesquisa com abordagem Qualitativa, onde se utilizou como pressupostos teórico-metodológicos elementos da Análise Conteúdo, Pesquisa Documental e Bibliográfica.

A Pesquisa Qualitativa, segundo Moreira (2004), apresenta como características o foco na interpretação que os próprios participantes têm da situação sob estudo, em vez de na quantificação; enfatiza aspectos da subjetividade, em vez de na objetividade; demonstra uma flexibilidade no processo de conduzir a pesquisa. Preocupando-se com o contexto, no sentido de que o comportamento dos indivíduos e a situação interligam-se intimamente na formação da experiência; reconhece o impacto do processo da pesquisa sobre a situação em foco e admite-se que o pesquisador exerce influência sobre a situação de pesquisa e é por ela também influenciado.

A Pesquisa Documental caracteriza-se por ter "fontes no sentido amplo, ou seja, não só de documentos impressos, mas outros tipos, com jornais, fotos, gravações, documentos legais". (SEVERINO, 2016, p. 131).

A Pesquisa Bibliográfica (SEVERINO, 2016): 
realiza-se a partir do registro disponível, decorrente de pesquisas anteriores, em documentos impressos, como livros, artigos, teses etc. utiliza-se de dados ou de categorias teóricas já trabalhadas por outros pesquisadores e devidamente registradas. Os textos tornam-se fontes dos temas a serem pesquisados. 0 pesquisador trabalha a partir das contribuições dos autores dos estudos analíticos constantes dos textos (p. 131).

A Análise de Conteúdo é um método muito empírico, segundo Bardin (2011), dependente do tipo de "fala" a que se dedica e do tipo de interpretação que se pretende como objetivo. É uma técnica ou um conjunto de técnicas que compreendem etapas ou fases que determinam sua análise. Estas fases são divididas em: pré-análise, nesta ocorre à organização da pesquisa, na qual material para ser analisado é escolhido, na sequencia se dá à formulação de hipóteses para análise; exploração do material, neste acontece à codificação das unidades de registro; por último ocorre o tratamento dos resultados, que os critérios de categorização e inferência. As categorias são uma forma de pensamento que reflete de forma resumida a realidade, na qual agrupam determinados elementos com características comuns.

A pesquisa foi realizada com 39 LD de Biologia (sendo 6 destes, volume único) e 22 LD de Ciências produzidos nos anos de 2002 a 2012 (Anexo I), segundo a ficha catalográfica, e que foram e alguns ainda são utilizados nas escolas públicas de João Pessoa-PB.

\section{RESULTADOS}

Dos LD de Biologia, 08 não apresentavam nenhum conteúdo em relação aos temas da pesquisa, já nos LD de Ciências foram 15.

Nos Quadros 01 e 02 são apresentadas a categorizações dos assuntos encontrados nos livros. Que inicia-se com a Categoria, que é a temática geral que foi pesquisada nos LD, na sequência, dentro da categoria, surgem constituintes, que são assuntos menos gerais que a categoria, e ainda nas constituintes ocorre as subconstituintes, que são temas mais específicos.

As frequências, ou seja, a quantidade de vezes que as subconstituintes estão presentes nos livros analisados divide-se em duas: a absoluta, que expressa de forma 
separada às constâncias de Biologia (representada pela letra B) e Ciências (representada pela letra C), e a relativa, que é dada em porcentagem e demonstra o total de frequência de cada subconstituinte, presente em todas as obras, ou seja, dos LD de Biologia e Ciências.

\section{Corpo}

São diversas e distintas as instituições e instâncias culturais e sociais que explicam como são e como devem ser os corpos e, para isso, utilizam-se das mais variadas táticas, estratégias e técnicas. A Biologia é uma delas. Mas, na condição de disciplina escolar, a abordagem sobre corpo deve ser compreendida a partir de sua inconstância, dado que suas necessidades e desejos mudam. O corpo se altera com a passagem do tempo, com mudanças de hábitos alimentares e de vida, com possibilidades distintas de prazer e de desejo ou com novas formas de intervenção médica e tecnológica (LOURO, 2008). Entretanto, a necessidade desta compreensão, por vezes, não é contemplada na educação básica e nem na formação inicial e/ou continuada dos professores, e concomitantemente, não efetivada na prática.

Relacionado aos livros de Biologia, na categorização destes, a constituinte "Fecundação", com a subconstituinte "Ciclo geral", que demonstra como ocorre o processo da fecundação que culmina no parto, foi a que obteve maior frequência relativa (quadro 1).

Quadro 1- Categorias e unidades de registro referente à temática Corpo presente nos livros de Ciências (C) e Biologia (B) produzidos de 2002 a 2012.

\begin{tabular}{|c|c|c|c|c|c|}
\hline \multirow{3}{*}{ Categoria } & \multirow{3}{*}{ Constituintes } & \multirow{3}{*}{ Subconstituintes } & \multicolumn{3}{|c|}{ Frequência } \\
\hline & & & \multicolumn{2}{|c|}{ Absoluta } & Relativa \\
\hline & & & B & C & $\%$ \\
\hline \multirow{9}{*}{ Corpo } & \multirow{3}{*}{ Fecundação/Ciclo } & Ciclo Geral & 22 & 5 & $19 \%$ \\
\hline & & Embriogenese/Formação do Feto & 13 & 4 & $11 \%$ \\
\hline & & Parto & 10 & 4 & $9 \%$ \\
\hline & Fisiologia & Puberdade & & 7 & $5 \%$ \\
\hline & Temas atuais & Aborto & 5 & 2 & $4 \%$ \\
\hline & \multirow[b]{2}{*}{ Gametogênese } & Espermatogênese & 11 & & $9 \%$ \\
\hline & & Ovogênese & 8 & & $7 \%$ \\
\hline & \multirow{2}{*}{ Anatomia } & $\begin{array}{l}\text { Órgãos e estruturas do sistema reprodutor } \\
\text { Feminino }\end{array}$ & 20 & 7 & $18 \%$ \\
\hline & & $\begin{array}{l}\text { Órgãos e estruturas do sistema reprodutor } \\
\text { Masculino }\end{array}$ & 20 & 6 & $18 \%$ \\
\hline
\end{tabular}

Fonte: Os autores. Baseado na análise de 22 livros de Ciências e 39 de Biologia. 
A subconstituinte com menor frequência, principalmente nos livros de Ciências, foi à temática "Aborto". Sobre este, nas obras de Amabis e Martho (2002, p. 414; 2008, p. 369 e 2011, p. 369) constatou-se equívocos a respeito do tema. Inicialmente o assunto estava localizado no tópico "métodos contraceptivos", dando a entender que o aborto também é uma forma de contracepção, pois em nenhum momento os autores relatam o contrário, na sequência, no decorrer do texto, mencionam qual seria o melhor tempo para uma mulher abortar com menor risco de morte da gestante e como realizar o procedimento, como expresso nesta frase dos autores: "Se realizado antes do terceiro mês de gestação, o aborto apresenta menos risco à saúde da mulher. A remoção cirúrgica do embrião é feita pela raspagem (curetagem) ou por aspiração da mucosa uterina com instrumentos de sucção)" (figura 1).

Figura 1 - Figura citada no texto.

\section{Aborto}

Aborto é a interrupção da gravidez pela morte do embrião ou do feto. Estima-se que, anualmente, no mundo, mais de 40 milhões de abortos sejam provocados, a maioria em condições precárias, com sérios riscos para a saúde da mulher.

A prática do aborto como método de controle da natalidade tem sido motivo de muitas discussões de cunho político, social e religioso. É grande o número de mulheres que morrem em conseqüência de abortos realizados por pessoas sem treinamento médico, nos países onde sua prática é ilegal.

Se realizado antes do terceiro mês de gestação, o aborto apresenta menos risco à saúde da mulher. A remoção cirúrgica do embrião é feita pela raspagem (curetagem) ou por aspiração da mucosa uterina com instrumentos de sucção.

Legenda: Trecho presente no livro de Amabis e Martho que expressa qual seria o melhor tempo para se abortar.

Fonte: Amabis e Martho (2002, p. 414; 2008, p. 369 e 2011, p. 369). 
Já em Favaretto e Mercadante (2005, p. 312) o tema aborto está também junto aos métodos contraceptivos, entretanto no primeiro parágrafo o autor explica que o "aborto não é um método anticoncepcional, pois consiste na interrupção de uma gestação já em andamento". Vale salientar que nenhum dos LD citados, e assim seus respectivos autores, explicitam a intenção, induzem ou estimulam o aborto, mas podem, em alguma situação, promover uma interpretação errônea por parte dos leitores, o que pode levar a prática de determinados atos e assim colocar vidas em risco.

Ainda em Amabis e Martho (2002, p. 411; 2011, p. 424) é importante ressaltar que de todos os livros analisados, são nestes dois que encontra-se as melhores explicações, utilizando de imagens e assim seguindo um dos critérios do PNLD, de como ocorre um parto (figura 2). Um fato preocupante durante as análises foi a ausência total da temática reprodução humana no livro de Borba et al. (2005), pois o mesmo é um LD de volume único e, concomitantemente, deveria trazer o assunto, pois, além disso, o conhecimento do próprio corpo é de grande significância para a formação da identidade e assim da prática social. Como cita Abílio (2010), a ausência de informações sobre esta temática, ao afetar o indivíduo, afeta a família, a sociedade e a escola, onde este último a ser citado encontra-se como um espaço sexualizado, ou seja, heterogêneo, não competindo à mesma silenciar frente a essas questões.

Outra temática em que percebeu-se informações equivocadas foi pertinente à fecundação, mais especificamente no processo de penetração do espermatozoide no óvulo. A obra de Silva Júnior e Sasson (2007, p. 333-334) menciona que "após um único espermatozoide penetrar no óvulo, o seu flagelo fica para fora", ou seja, o flagelo não penetra no óvulo e, como demonstrado na imagem abaixo, acaba perdendo-se (figura 3). 
Figura 2 - Figura citada no texto.

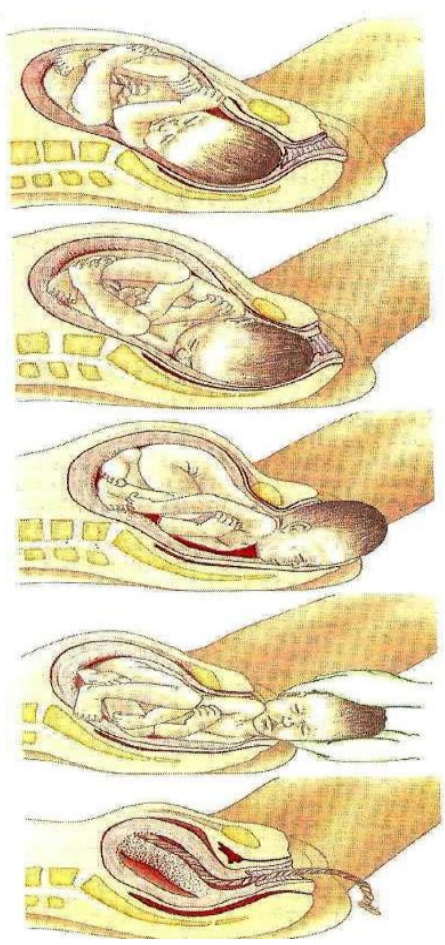

(B)

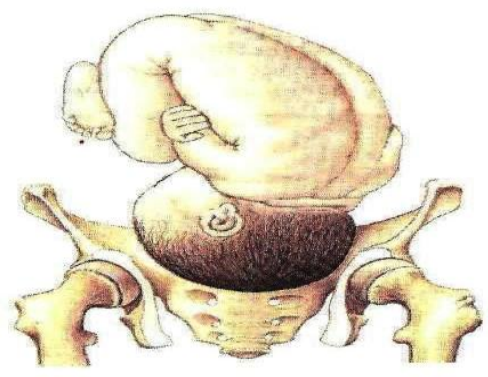

(C)
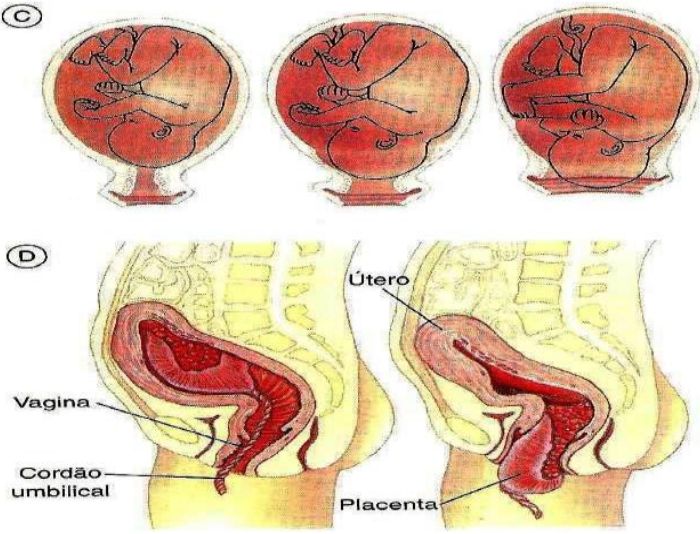

Legenda: Etapas de parto no ser humano, explicando a orientação correta em relação à pelve da mãe como também as modificações ocorridas no útero.

Fonte: Amabis e Martho (2002, p. 411; 2011, p. 424).

Figura 3 - Figura citada no texto.
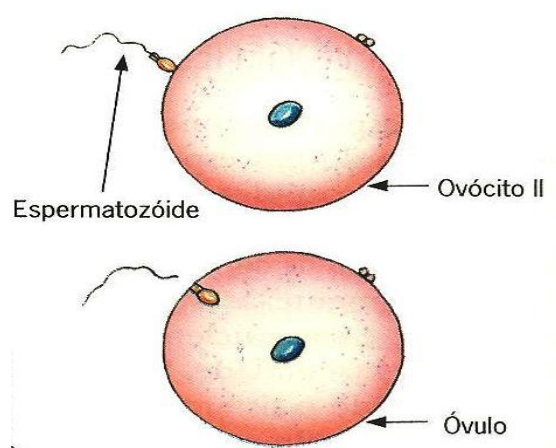

Penetração do espermatozóide
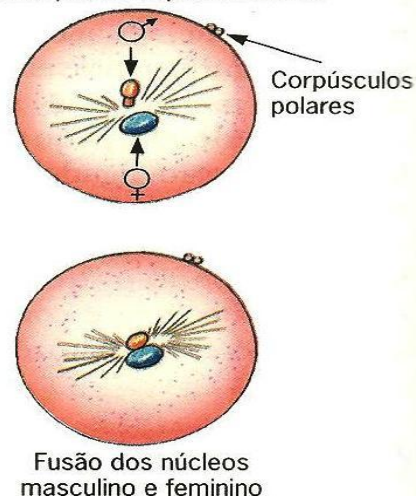

Legenda: Esquema do processo de fecundação aonde o espermatozoide perde seu flagelo na entrada no óvulo.

Fonte: Silva Júnior e Sasson (2007, p. 334). 
Entretanto, nos livros de Linhares e Gewandsznajder (2007, p. 306; 2011, p. 306), demonstra-se que quando o espermatozoide penetra no óvulo, o flagelo adentra também, ou seja, não se perde durante o processo. (figura 4). E como afirma Sebastião (2014), no site oficial do Conselho Regional de Medicina da Paraíba (CRM-PB), um dos principais erros existentes nos LD de Biologia é a informação que o flagelo não penetra, uma vez que o mesmo também penetra no citoplasma do óvulo.

Figura 4 - Figura citada no texto.

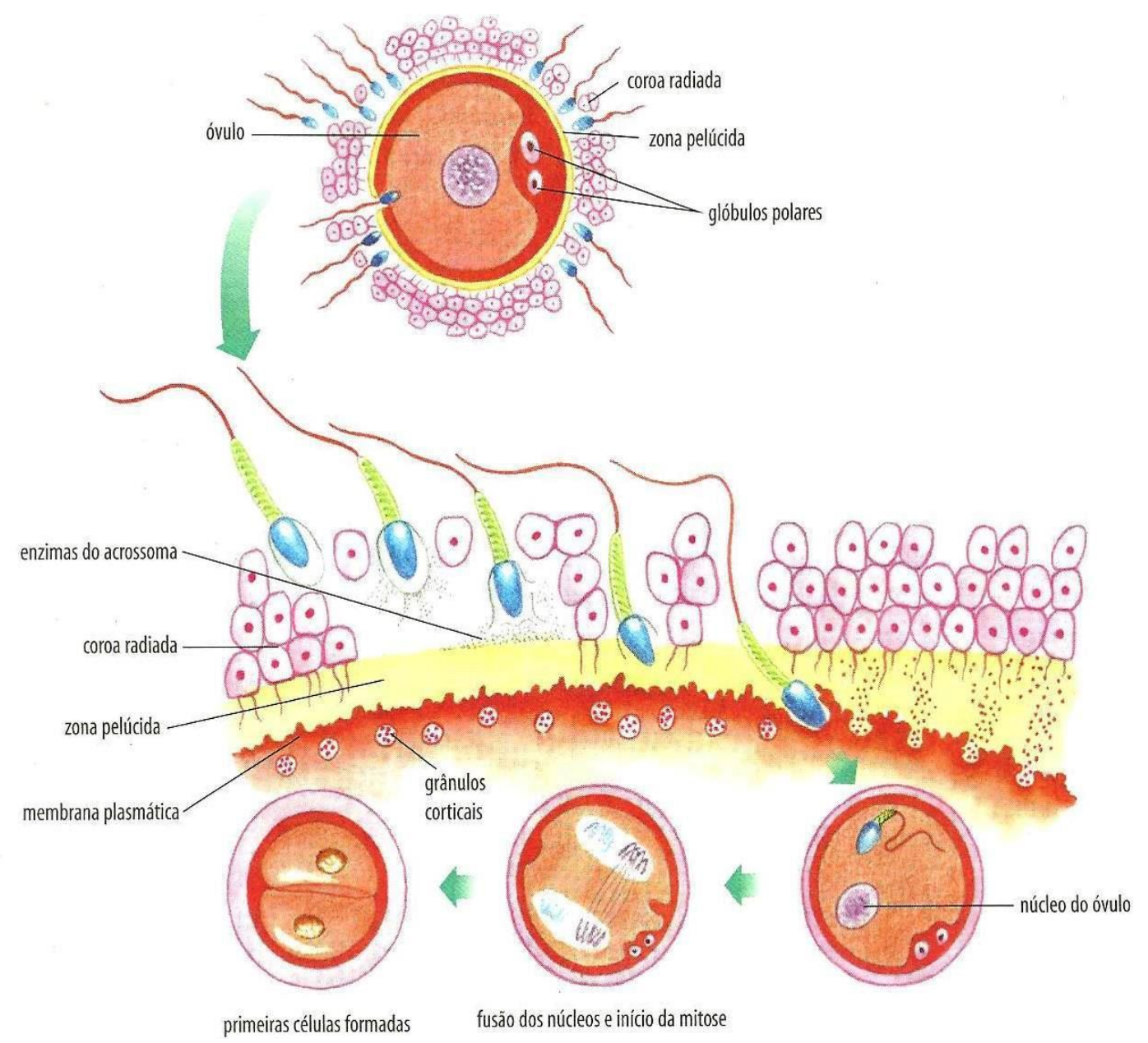

Legenda: Esquema do processo de fecundação na qual o espermatozoide continua com flagelo após a entrada no óvulo.

Fonte: Linhares e Gewandsznajder (2007, p. 306; 2011, p. 306).

Já nos livros de Ciências, especificamente em Luz e Santos (2002, p. 95), existe um erro relacionado aos ovários, onde os autores citam que "quando a menina nasce, seus 
ovários já possuem, em conjunto, 500 mil folículos primários" (figura 5). Entretanto, segundo Araldi e Armiliato (2005), no córtex, estão presentes pequenas formações, os folículos ovarianos, que sofrem a ação de hormônios hipofisiários, originando os óvulos. Quando uma menina nasce apresenta no córtex cerca de 200.000 folículos, totalizando aproximadamente 400.000 folículos ovarianos. Este número cai para 10.000 na puberdade e nenhum na menopausa.

Figura 5 - Figura citada no texto.

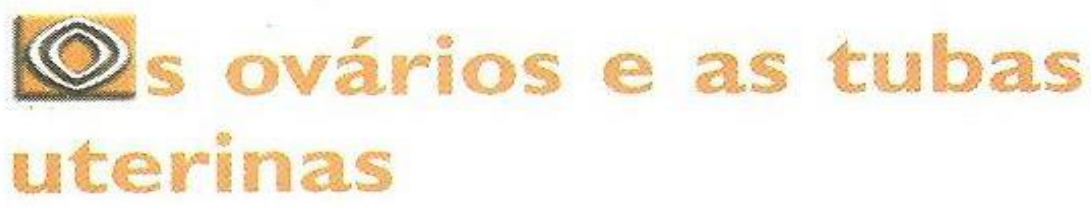

Quando a menina nasce, seus ovários já possuem, em conjunto, cerca de 500 mil folículos primários, de onde vão surgir os óvulos maduros, prontos para serem fecundados. Dos $500 \mathrm{mil}$ "candidatos" a óvulos maduros, somente uns 500 alcançarão esse objetivo. Os outros acabarão por degenerar-se.

Legenda: Informação retirada do livro que expressa de forma equivocada sobre os folículos primários.

Fonte: Luz e Santos (2002, p. 95).

Ainda nos LD de Ciências, apenas Barros e Paulino (2008, p. 57) demonstram, em imagens, como ocorre um parto do tipo cesariano (figura 6). Todavia os autores esclarecem que este tipo de parto só deve ser realizado em casos de dificuldades que impedem o parto normal, ou seja, quando o bebê está em posição inadequada ou quando a mãe não apresenta condições de suportar o processo normal. 
Figura 6 - Figura citada no texto.

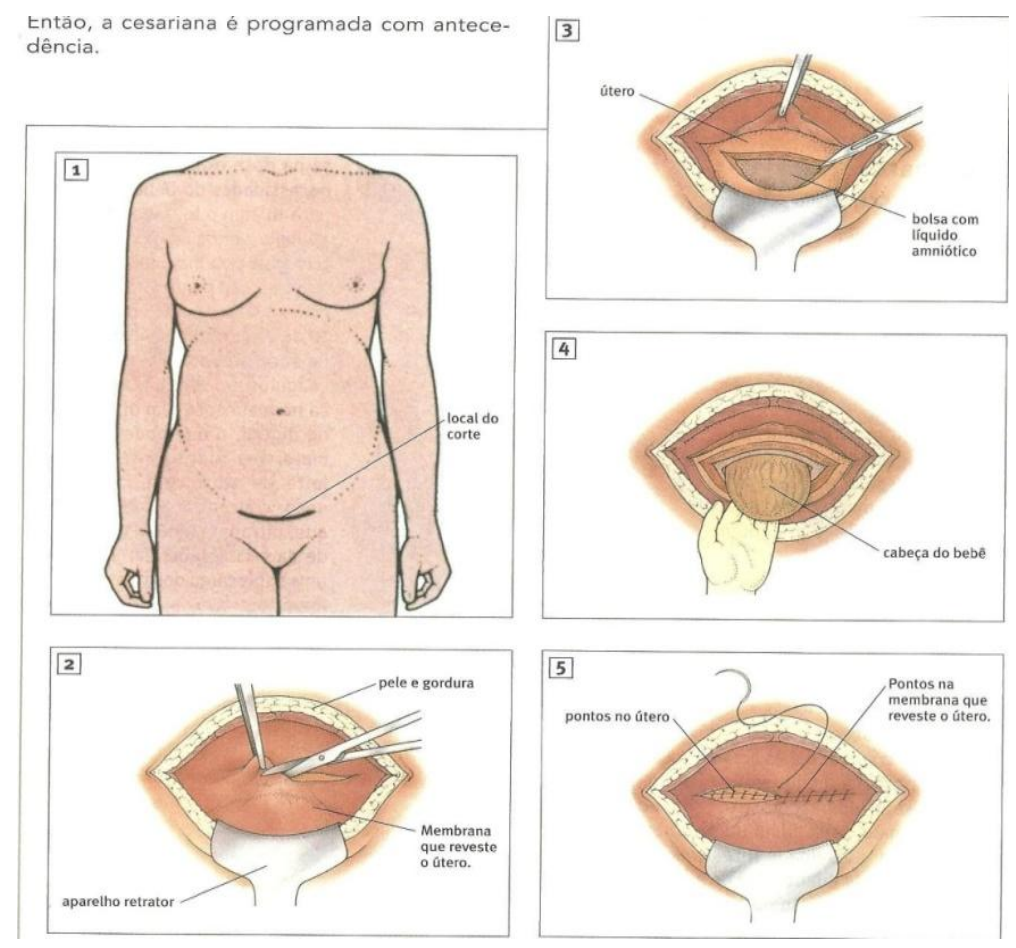

Legenda: Imagem retirada do livro explicando como ocorre o processo de parto pelo método Cesário. Fonte: Barros e Paulino (2008, p. 57).

Corroborando, Barbosa et al. (2003) alerta sobre os riscos ainda existentes com o parto cesariano:

sendo este um procedimento originalmente desenvolvido para salvar a vida da mãe e/ou da criança, quando ocorrem complicações durante a gravidez ou o parto. Mas como todo procedimento cirúrgico, a cesárea não é isenta de riscos, estando associada, no Brasil e em outros países, a maior morbimortalidade materna e infantil, quando comparada ao parto vaginal (p.1612).

Ainda neste sentido, Nomura et al. (2004) afirma que nos últimos anos, o Brasil vem apresentando uma das mais elevadas taxas de cesáreas do mundo. Muitos fatores apresentam-se relacionados a este fato e envolvem, principalmente, o aprimoramento de técnicas cirúrgicas e anestésicas, mesmo assim, ainda os riscos são evidentes, tanto para a mãe, como para o filho. 
Um fato interessante e contestável, uma vez que a puberdade ainda ocorre com estudantes do ensino médio (média de idade entre 14 e 17 anos), é a presença da subconstituinte "Puberdade" apenas nos LD de Ciências, tal questão pode-se relacionar ao início deste processo ocorrer quando a maioria dos estudantes encontram-se no ensino fundamental. Como afirma, Campagna e Souza (2006):

\begin{abstract}
as mudanças corporais que ocorrem nas garotas, nessa fase do desenvolvimento, são consideráveis. Desencadeadas pela produção dos hormônios, a partir dos oito ou nove anos, promovem mudanças no tamanho do corpo, nas suas proporções, e o desenvolvimento das características sexuais primárias e secundárias. O surto de crescimento da puberdade começa um ano ou dois antes que os órgãos sexuais amadureçam, e depois disso, dura de seis meses a um ano. Nas meninas começa entre 8,5 e 11,5 anos, com um pico de rapidez que ocorre em média aos 12,5 anos, declinando depois disso até parar por volta de 15 a 16 anos. 0 crescimento em altura segue um padrão regular e geralmente precede o aumento de peso. Em cerca de três anos, até um ano depois da puberdade, a menina ganha, em média, 17 quilos (p. 10, grifo nosso).
\end{abstract}

Sobre a puberdade, por ser uma etapa de muitas modificações fisiológicas, anatômicas, psicológicas e etc. com os adolescentes, o docente tem grande significância na mediação e sistematização desta temática. Lembrando que a família também tem sua colaboração na formação do sujeito.

Outra questão importante, presente no livro de Nahas et al. (2010, p.169-170), é sobre a "manutenção" ou "perda" da virgindade com a presença ou não do hímen na mulher. Os autores, no decorrer do texto, buscam, através do conhecimento científico, ultrapassar os estereótipos e dogmas ainda presente em nossa sociedade sobre o tema quando afirmam que: "por que os homens podem expressar seu tesão e transar e as mulheres não? .... Hoje a mulher pode decidir por motivos dela, só dela, se quer começar a vida sexual antes ou após o casamento." Os autores ainda demonstram, por meio de imagem, diferentes variações do hímen (Figura 07), sua posição (mencionando que o homem não percebe se a mulher é ou não "virgem"). 
Figura 07 - Figura citada no texto.
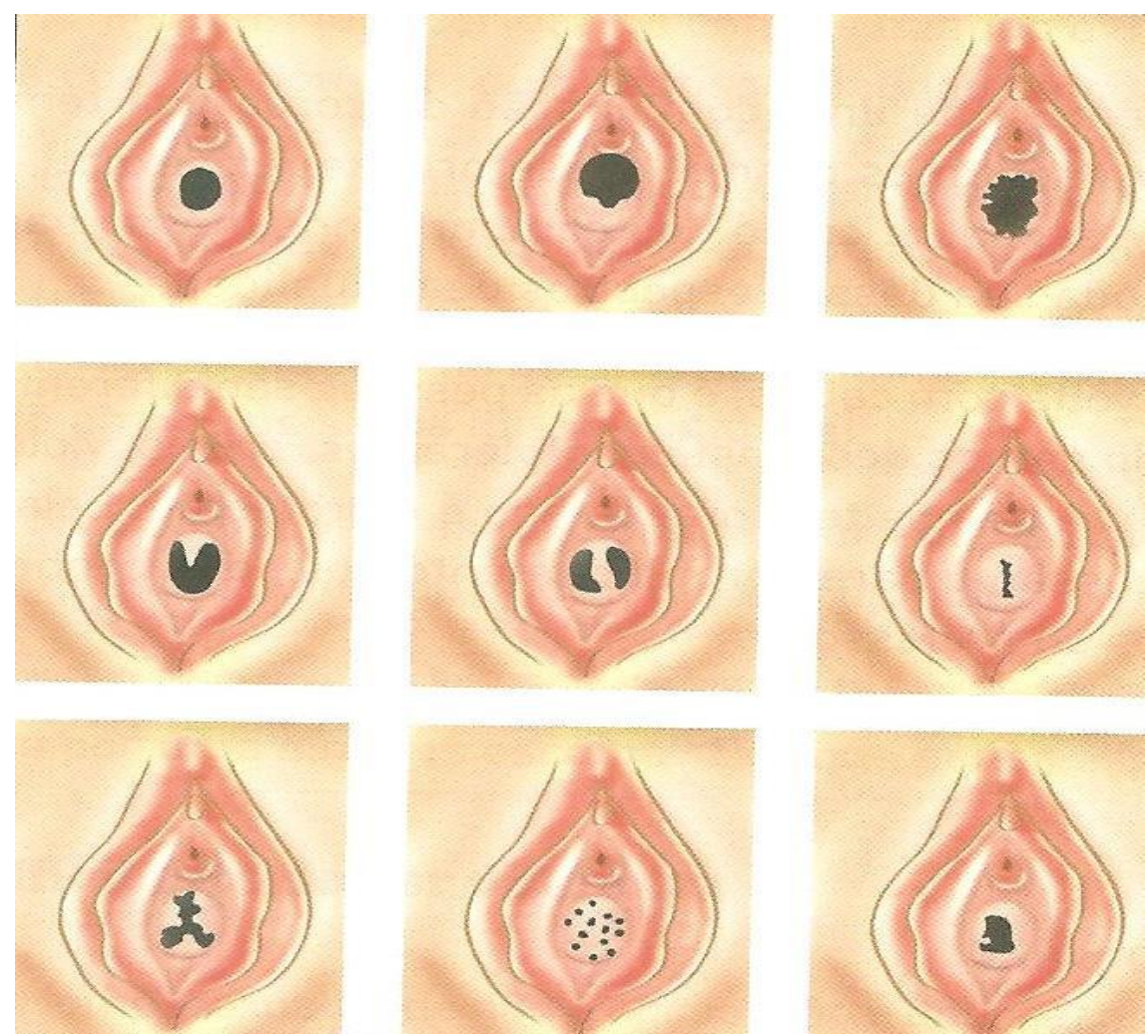

Legenda: Diferentes variações de formato anatômico do hímen no órgão genital feminino. Fonte: Nahas et al. (2010, p.169-170).

\section{Infecções Sexualmente Transmissíveis}

As IST são transmitidas, principalmente, durante a relação sexual, ocorrendo quando uma pessoa não infectada tem contato sexual com outra já infectada, as manifestações mais normais de uma IST é o aparecimento de verrugas, corrimentos e dores na região genitália.

Nos livros de Biologia, em seu processo de categorização, a IST que ocorre com maior frequência absoluta é a sífilis (com frequência absoluta 28) (quadro 2). Já nos LD de Ciências, é a AIDS que tem maior frequência absoluta. Durante a análise é perceptível à ausência e informações incompletas em diversas abordagens nos LD sobre algumas IST. 
Quadro 2 - Categorias e unidades de registro referente à temática IST (Características e Agentes Etiológicos) presente nos livros de Biologia, de 2002 a 2012.

\begin{tabular}{|c|c|c|c|c|c|}
\hline \multirow[t]{3}{*}{ Categoria } & \multirow[t]{3}{*}{ Constituintes } & \multirow[t]{3}{*}{ Subconstituintes } & \multicolumn{3}{|c|}{ Frequência } \\
\hline & & & \multicolumn{2}{|c|}{ Absoluta } & \multirow{2}{*}{$\begin{array}{c}\text { Relativa } \\
\%\end{array}$} \\
\hline & & & B & C & \\
\hline \multirow{13}{*}{$\begin{array}{c}\text { Infecções } \\
\text { Sexualmente } \\
\text { Transmissíveis }\end{array}$} & \multirow{5}{*}{$\begin{array}{l}\text { Causadas por } \\
\text { Bactérias }\end{array}$} & Sífilis & 28 & 6 & $15 \%$ \\
\hline & & Cancro Mole & 11 & & $5 \%$ \\
\hline & & Gonorreia & 25 & 5 & $14 \%$ \\
\hline & & $\begin{array}{l}\text { Linfogranuloma } \\
\text { Venéreo }\end{array}$ & 10 & 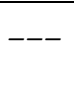 & $5 \%$ \\
\hline & & Clamidíase & 5 & 2 & $3 \%$ \\
\hline & \multirow{5}{*}{$\begin{array}{l}\text { Causadas por } \\
\text { Vírus }\end{array}$} & $\begin{array}{l}\text { Condiloma } \\
\text { Acuminado }\end{array}$ & 20 & 6 & $12 \%$ \\
\hline & & AIDS & 27 & 7 & $15 \%$ \\
\hline & & Herpes Genital & 15 & 3 & $8 \%$ \\
\hline & & Citomegalovirose & 3 & --- & $1 \%$ \\
\hline & & $\begin{array}{l}\text { Hepatite B e/ou C } \\
\text { e/ou D. }\end{array}$ & 10 & 1 & $5 \%$ \\
\hline & $\begin{array}{l}\text { Causadas por } \\
\text { Fungos }\end{array}$ & Candidíase & 6 & 1 & $3 \%$ \\
\hline & $\begin{array}{l}\text { Causadas por } \\
\text { Protozoários }\end{array}$ & Tricomaníase & 20 & 4 & $11 \%$ \\
\hline & $\begin{array}{l}\text { Causadas por } \\
\text { Insetos }\end{array}$ & $\begin{array}{l}\text { Pediculose } \\
\text { Pubiana }\end{array}$ & 6 & 2 & $3 \%$ \\
\hline
\end{tabular}

Fonte: Dados da pesquisa. Baseado na análise de 22 livros de Ciências e 39 de Biologia.

Sobre a Sífilis, um dado de extrema alerta é disponibilizado pela Secretaria de Saúde do estado de São Paulo, na qual informam que as ocorrências de sífilis por transmissão sexual cresceram 603\% em seis anos. O salto foi de $2694 \mathrm{em} 2007$ para $18951 \mathrm{em} \mathrm{2013.} \mathrm{Em}$ outros estados, o panorama não é menos preocupante. Em 2013 e 2014, Acre, Pernambuco e Paraná registraram crescimento de $96,1 \%, 94,4 \%$ e $63,1 \%$, respectivamente ${ }^{2}$.

Em Favaretto e Mercadante (2005), apenas é citado algumas IST, sendo em um capítulo que inclui vírus, bactérias e fungos. Entretanto, por este ser um livro volume único, deveria discutir a temática com maior veemência e solidez. Em Linhares e Gewandsznajder (2003, p. 444-445), também volume único, menciona-se as IST de forma muito superficial,

\footnotetext{
${ }^{2}$ Aumento dos casos de Sífilis. Fonte: Disponível em: https://saude.abril.com.br/bem-estar/numero-de-infeccoessexualmente-transmissiveis-nao-para-de-crescer/ Acesso em: 31 jan. 2016.
} 
como ocorre na caracterização da Gonorreia, afirmando que "é causada pela bactéria Neisseria gonorrhoeae, e que pode provocar inflamação da uretra, da próstata e do útero. Pode haver dor, ardência e uma secreção branca ou amarelada ao urinar. A secreção vaginal pode ficar amarelada". Não havendo explicação das formas de prevenção e tratamento. E ainda algumas infecções como Cancro mole e Linfogranuloma Venéreo sequer foram abordadas no livro.

Na obra de Lopes e Rosso (2007; 2008), não materalizam-se à presença de algumas IST, mas o que é alarmante é a ausência da Clamidíase, uma grave IST que acomete quase $10 \%$ das jovens brasileiras atendidas pelo SUS, segundo estudo divulgado Secretaria Estadual da Saúde do Estado de São Paulo ${ }^{3}$. Corroborando com a informação acima, Jalil et al. (2008), menciona que a Organização Mundial de Saúde (OMS):

estima que a cada ano ocorram em torno de 92 milhões de novos casos de clamídia, das quais a maioria acontece em países em desenvolvimento, afetando principalmente jovens. O Centro de Controle de Doenças (CDC) dos Estados Unidos da América estima que, anualmente, metade das novas infecções sexualmente transmissíveis no mundo ocorra entre 15 e 24 anos, o que representa mais de 9 milhões de jovens infectados, dos quais estima haver 2,8 milhões de casos de clamidíase (p. 615).

No Brasil são raros os serviços de saúde que oferecem sistematicamente a pesquisa dessas bactérias como parte de uma consulta ginecológica ou de pré-natal. A Organização Mundial de Saúde (OMS) também lista as doenças sexualmente transmissíveis de maior recorrência no Brasil. Sendo a Clamídia que apresenta maior número de casos com 1.967.200, seguido da gonorreia com 1.541 .800 e da sífilis com 937.000. Já o número de soropositivos registrados pelo Ministério da Saúde chegou a 592.914 desde a década de 1980 até $2010^{4}$.

Mas é tratando-se da Hepatite que ocorre várias informações incompletas, equívocos e divergências entre os escritos dos autores nos LD analisados. Primeiramente a obra de Bizzo (2012) não explicita nada relacionado à transmissão das hepatites pelo ato sexual. Em Linhares e Gewandsznajder (2003, p. 445) menciona apenas da hepatite B como uma IST,

\footnotetext{
${ }^{3}$ Fonte: Conselho de Saúde do Mato Grosso. Disponível em: https://veja.abril.com.br/saude/uma-em-cada-dezjovens-atendidas-pelo-sus-em-sao-paulo-tem-clamidia-diz-pesquisa/ Acesso em: 21 fev. 2018.

${ }^{4}$ Fonte: Ministério da Saúde. Disponível em: http://www.brasil.gov.br/saude/2011/09/hiv-e-dst-em-mulheres. Acesso em: 10 set. 2018.
} 
todavia a hepatite $C$ também é transmitida por ato sexual e que os programas devem incluir como forma de transmissão as atividades de risco, como o uso de drogas e sexo não protegido (Ferreira; Silveira, 2004). Já Fonseca (2002, p. 183) explicita que "a transmissão da hepatite D (VHD) também ocorre pela relação sexual, já que apresenta os mesmos mecanismos de transmissão da hepatite B (VHB)". Ainda Linhares e Gewandsznajder (2003), apesar da hepatite B está localizado no grupo das IST, as informações presentes, principalmente com relação à transmissão, não demonstram que ocorre por ato sexual, como demonstra na figura abaixo (figura 8).

Figura 8 - Figura citada no texto.

Hepatiite B. É causada por vírus, que pode provocar, em alguns casos, destruição (cirrose) ou câncer do fígado. O vírus pode passar da mãe para o filho no parto. Por isso, logo ao nascer, a criança deve tomar a primeira dose da vacina, que deverá ser repetida um mês depois e, novamente, seis meses depois da primeira dose. Adultos também podem tomá-la. (O vírus também pode ser transmitido por transfusão de sangue e por contato dos tecidos que forram a boca e outras cavidades com secreções, como saliva e lágrimas.)

Legenda: Recorte textual retirada do livro, na qual não expressa que a Hepatite B pode ser transmitida pela relação sexual.

Fonte: Linhares e Gewandsznajder (2003, p. 445).

Já em Paulino (2008, p. 31-32) é explicado, inicialmente, sobre todos os tipos de hepatites existentes (de A a $G$ ), todavia menciona-se que a $B$ e a $C$ podem ser transmitidas durante o sexo, faltando a informação de que a $\mathrm{D}$ também pode ocorrer durante a relação sexual, como foi anteriormente citado.

Silva Júnior e Sasson (2006, p. 213) relacionam as hepatites B e C como sendo transmitidas por relação sexual, contudo, não caracterizam os sinais e o modo de 
prevenção. Uma vez que os critérios estabelecidos pelos PNLD enfatizam a necessidade dos LD apresentarem, quando trata-se de IST, os modos de prevenção das doenças.

A explicação mais detalhada com relação às hepatites está em Amabis e Martho (2006, p. 49) e Linhares e Gewandsznajder (2011, p. 37), estes explicam que a B, C e D podem ser transmitidas durante o ato sexual.

Já nos livros de Ciências, Luz e Santos (2002, p. 103-104) demonstram uma tabela com algumas IST e nesta ocorre informações incompletas e confusas sobre o causador da sífilis. Na qual no livro expressa que é a espiroqueta, entretanto a bactéria causadora é a Treponema pallidum. Outra informação incompleta foi de mencionar que tanto a herpes genital, como a AIDS são causados por vírus, mas sem especificar o nome da espécie, sendo a primeira causada pelo vírus do herpes simples (HSV) e a outra pelo vírus HIV.

Em Trivellato et al. (2006, p. 176) também ocorre a presença de uma tabela com várias IST e o causador (se é um vírus, bactérias e etc.), este fato é importante na organização e sistematização das ideias por parte dos educandos, pois o uso de tabelas pode facilitar a aprendizagem.

$\mathrm{Na}$ quase totalidade dos LD de Ciências analisados, quando a temática é vírus, só é mostrado, com ciclo, a AIDS, como ocorreu em Porto e Mattos (2005) e Gewandsznajder (2007). Ou seja, ocorre ocultação de informação acerca das outras IST transmitidas paro vírus.

Os equívocos que ocorrem pertinente a IST Hepatite nos LD de Biologia também encontra-se nos de Ciências, pois em Barros e Paulino (2008, p. 68) é mencionado que apenas as Hepatites B e C são transmitidas pelo ato sexual, e como foi mostrado anteriormente, a D também pode ser.

\section{CONCLUSÃO E CONSIDERAÇÕES FINAIS}

Nas obras analisadas são perceptíveis equívocos e informações imprecisas, como ocorre quando o tema é "Corpo", como, por exemplo, sobre a não entrada do flagelo do espermatozoide no citoplasma do óvulo no processo de fecundação, e quando explicita a melhor forma e o tempo "apropriado" para fazer o aborto. Já sobre as IST os problemas 
evidenciam-se de modo mais pertinente quando o tema é Clamidíase e sobre tipos de hepatites que são transmitidas no ato sexual.

Assim percebe-se a incompletude da abordagem das IST nos LD, podendo-se tornar um agravante em sala de aula. Neste sentido, os autores e editoras devem estabelecer uma maior vinculação entre os conteúdos tratados nos livros e as propostas contidas nos PCN com relação ao eixo temático "Ser Humano e Saúde", de forma crítica. Deste modo, a falta de informações pode reduzir as possibilidades dos educandos identificarem em si os primeiros sinais e consequentemente uma demora das notificações nos setores da saúde.

Um fato significante durante a pesquisa ocorreu em alguns livros de Ciências, na qual o debate sobre o corpo materializa-se não apenas numa dimensão anatômica e fisiológica, mas sociocultural. Sendo este processo de extrema importância na formação da identidade do ser humano. Já nos LD de Biologia dificilmente discutia-se a temática nesta perspectiva, quando ocorria, era apenas com indicações de leituras e filmes complementares.

De modo geral, os critérios estabelecidos pelo PNLD são contemplados apenas paro alguns LD e de modo parcial. Assim, evidencia-se a importância dos professores adotarem critérios para a escolha dos LD, assim como analisarem este recurso didático, procurando utilizar outras fontes e instrumentos de ensino para a realização das aulas.

Durante a análise é perceptível mudanças e aprimoramentos em vários aspectos dos LD, na qual, no caso das imagens e dos textos complementares, os livros produzidos de 2010 a 2012 contemplam mais os critérios do PNLD em comparação aos livros publicados de 2002 a 2005.

Portanto, no desenvolvimento das análises, ficou perceptível que alguns LD apresentam equívocos conceituais, o que pode levar erros procedimentais e atitudinais. Deste modo, pode-se afirmar que o LD não deve ser o único recurso utilizado pelo professor na sala de aula.

\section{REFERÊNCIAS}

ABÍLIO, Francisco José Pegado. Educação, Meio Ambiente e Saúde nas Escolas. In: GUERRA, R.A.T. (Org.). Ciências Biológicas: Cadernos CB Vitual 6. 01ed. v. 06. João Pessoa: Editora Universitária - UFPB, 2010. 
Corpo e infecções sexualmente transmissíveis: análise

dos conteúdos nos livros didáticos de ciências e biologia

BARBOSA, G. P.; GIFFIN, K.; ANGULO-TUESTA, A.; GAMA, A. S.; CHOR, D.; D'ORS, I.; REIS, E. A. C. G. V. Parto cesáreo: quem o deseja? Em quais circunstâncias? Rev. Cad. Saúde Pública, Rio de Janeiro. v. 19, n.6, p.16111620, nov./dez., 2003.

BARDI, J.; CAMPOS, L. M. L. Orientação Sexual nas séries iniciais do Ensino Fundamental. Associação Brasileira de Pesquisa em Educação em Ciências. n.5, p.1-12, 2005

BARDIN, L. Análise de conteúdo. São Paulo: Edições 70, 2011.

BIZZO, N. Graves Erros de Conceito em Livros Didáticos de Ciência. Ciência Hoje. v.21, n.121, p.26-35, 1996.

BIZZO, N. Ciências: fácil ou difícil? São Paulo: Editora Ática, 2002.

BRASIL. Parâmetros Curriculares Nacionais Ensino Médio. Secretaria de Educação Fundamental, Brasília, DF: MEC/SEF, 2000.

BRASIL. Ministério da Educação e do Desporto. Secretaria de Educação Fundamental. Parâmetros Curriculares Nacionais: Temas Transversais. Brasília: MEC/SEF, 2001.

BRASIL. PCN+ Ensino Médio: Orientações educacionais complementares aos PCN. Ciências da Natureza, Matemática e suas Tecnologias. Secretaria de Educação Média e Tecnológica, Brasília: MEC/SEMTEC, 2002.

BRASIL. Programa Nacional do Livro Didático (PNLD). Guia dos Livros Didáticos de Ciências Naturais. Brasília, DF: MEC, 2013.

BRASIL Programa Nacional do Livro Didático (PNLD). Guia dos Livros Didáticos de Biologia. Brasília, DF: MEC, 2014.

AMPAGNA, V. N.; SOUSA, A. S. L. Corpo e imagem corporal no início da adolescência feminina. Boletim de Psicologia. v.61, n.124, p.09-35, 2006.

CORRÊA, G. F. P. Corpo e Sexualidade na Contemporaneidade. III SIMPÓSIO INTERNACIONAL DE EDUCAÇÃO SEXUAL. Anais... Maringá, 2013.

COSTA, A. P. As concepções de sexualidade de um grupo de alunas do curso de Pedagogia: uma análise a partir do recorte de gênero. Dissertação (Mestrado em Educação Escolar), Faculdade de Ciências e Letras, Universidade Estadual Paulista, Campus de Araraquara - SP, 2009.

FERREIRA, C. T.; SILVEIRA, T. R. Hepatites Virais: Aspectos de epidemiologia e prevenção. Rev. Bras. Epidemiologia. v.7, p.473-87, 2004.

FONSECA, J. C. F. HEPATITE D. Rev. Eletrônica soc. Bras. Med. Trop. v.35, p.2, Uberaba-MG, MAR./ABR, 2002.

FOUCAULT, M. História da sexualidade: à vontade de saber. 1 (12), Rio de Janeiro: Graal, 1997.

JALIL, E. M.; PINTO, V. M.; BENZAKEN, A. S.; RIBEIRO, D.; OLIVEIRA, E. C.; GARCIA, E. G.; MOHERDAUI, F.; BARBOSA, M. J. Prevalência da infecção por clamídias e gonococo em gestantes de seis cidade brasileiras. Rev. Bras. Ginecolologia Obstet. v.30, n.12, p.614-619, 2008.

KACELNIK, J. Guina de orientação sexual: diretrizes e metodologia da pré-escola ao segundo grau. São Paulo: Casa do Psicólogo, 1994.

KRASILCHIK, M. Prática de Ensino de Biologia. São Paulo: Editora da Universidade de São Paulo, 2004.

LOURO, G. L. (Org.). o Corpo Educado: pedagogias da sexualidade. 2. Belo Horizonte: Edição Autêntica, 2000.

LOURO, G. L. Gênero e sexualidade: pedagogias contemporâneas. Rev. Pro-Posições. 2008. Disponível em: < http://www.scielo.br/pdf/pp/v19n2/a03v19n2.pdf >. Acesso em: 10 set. 2018. 
MARCONI, M. A.; LAKATOS, E. M. Fundamentos de Metodologia Científica. São Paulo: Atlas, 2005.

MOREIRA, D. A. O Método Fenomenológico na Pesquisa. São Paulo: Pioneira, 2004.

NOMURA, R. M. Y.; ALVES, E. A.; ZUGAIB, M. Complicações maternas associadas ao tipo de parto em hospital universitário. Rev. Saúde Pública. v.38, p.9-15, 2004.

RIBEIRO, P. R. C.; SOUZA, N. G.; SOUZA, D. Sexualidade na sala de aula: pedagogias escolares das professoras das séries iniciais do Ensino Fundamental, Revista Estudos Feministas. v.12, n.1, 2004.

SEBASTIÃO, E.Os Erros nos Livros Didáticos. 2014. Disponível em: < http://www.crmpb.cfm.org.br/index.php?option=com_content\&view=article\&id=20991:\&catid=3 > Acesso em: 10. Set. 2018.

SEVERINO, A. J. Metodologia do Trabalho Científico. São Paulo: Cortez, 2016.

SILVA, H. C. . Cautela ao usar imagens em aula de ciências. Rev. Ciência e Educação. v.12, n.2, p.219-233. 2006.

WEEKS, J. O corpo e a sexualidade. In: Louro, G. L(Org.). o corpo educado: pedagogias da sexualidade. Belo Horizonte: Autêntica, p 35-82, 2007. 
Corpo e infecções sexualmente transmissíveis: análise dos conteúdos nos livros didáticos de ciências e biologia

ANEXO I - Referências dos LD categorizados e analisados.

\section{LD DE BIOLOGIA}

ADOLFO, A.; CROZETA, M.; LAGO, S. Biologia: volume único. São Paulo: IBEP, 2005.

AMABIS, J. M.; MARTHO, G. R. Biologia. V. 1. 2º ed. São Paulo: Moderna, 2011.

AMABIS, J. M.; MARTHO, G. R. Biologia. V. 1. 2º ed. São Paulo: Moderna, 2008.

AMABIS, J. M.; MARTHO, G. R. Biologia. V. 2. 2º ed. São Paulo: Moderna, 2006.

AMABIS, J. M.; MARTHO, G. R. Biologia. V. 3. 2º ed. São Paulo: Moderna, 2009.

AMABIS, J. M.; MARTHO, G. R. Conceitos de Biologia. V. 1. São Paulo: Moderna, 2002.

BIZZO, N. Novas Bases da Biologia: seres vivos e comunidades. V. 2. 1ํed. São Paulo: Ática, 2012.

BORBA, A. A.; CROZETTA, M. A. S. LAGO, Samuel Ramos. Biologia: volume único. 2. ed. São Paulo: 2005.

FAVARETTO, J. A.; MERCADANTE, C. Biologia: volume único. 1ํed. São Paulo: Moderna, 2005.

GEWANDSZNAJDER, F.; LINHARES, S. Biologia: volume único. São Paulo: Ática, 2007.

LAURENCE, J. Biologia: ensino médio, volume único. 1º ed. São Paulo: Nova Geração, 2009.

LINHARES, S.; GEWANDSZNAJDER, F. Biologia Hoje. V. 1. 1ํed. São Paulo: Ática, 2011b.

LINHARES, S.; GEWANDSZNAJDER, F. Biologia Hoje. V. 2. 1ํe․ São Paulo: Ática, 2011a.

LINHARES, S.; GEWANDSZNAJDER, F. Biologia Hoje. V. 3. 1ํe. edão Paulo: Ática, 2011c.

LINHARES, S.; GEWANDSZNAJDER, F. Biologia Hoje. V. 2. 11ํe․ São Paulo: Ática, 2003.

LOPES, S. G. B. C. Bio. V. 1. 1 ed. São Paulo. Saraiva, 2002.

LOPES, S. Bio: volume único. 2º ed. São Paulo. Saraiva, 2008.

LOPES, S.; ROSSO, S. Biologia: V. 1. 1ํed. São Paulo. Saraiva, 2010a.

LOPES, S.; ROSSO, S. Biologia: V. 2. 1º ed. São Paulo. Saraiva, $2010 b$.

LOPES, S.; ROSSO, S. Biologia: volume único. 1 ed. São Paulo. Saraiva, 2008.

LOPES, S.; ROSSO, S. Biologia: volume único. 1 ed. São Paulo. Saraiva, 2007.

MENDONÇA, V.; LAURENCE, J. Biologia. V. 1. 1º ed. São Paulo: Nova Geração, 2010a.

MENDONÇA, V.; LAURENCE, J. Biologia. V. 2. 1ํe. São Paulo: Nova Geração, 2010 b.

MENDONÇA, V.; LAURENCE, J. Biologia. V. 3. $1^{\circ}$ ed. São Paulo: Nova Geração, 2010c.

PAULINO, W. R. Biologia. V. 1. 1º ed. São Paulo: Ática, 2009a.

PAULINO, W. R. Biologia. V. 1. 1ํed. São Paulo: Ática, 2008a. 


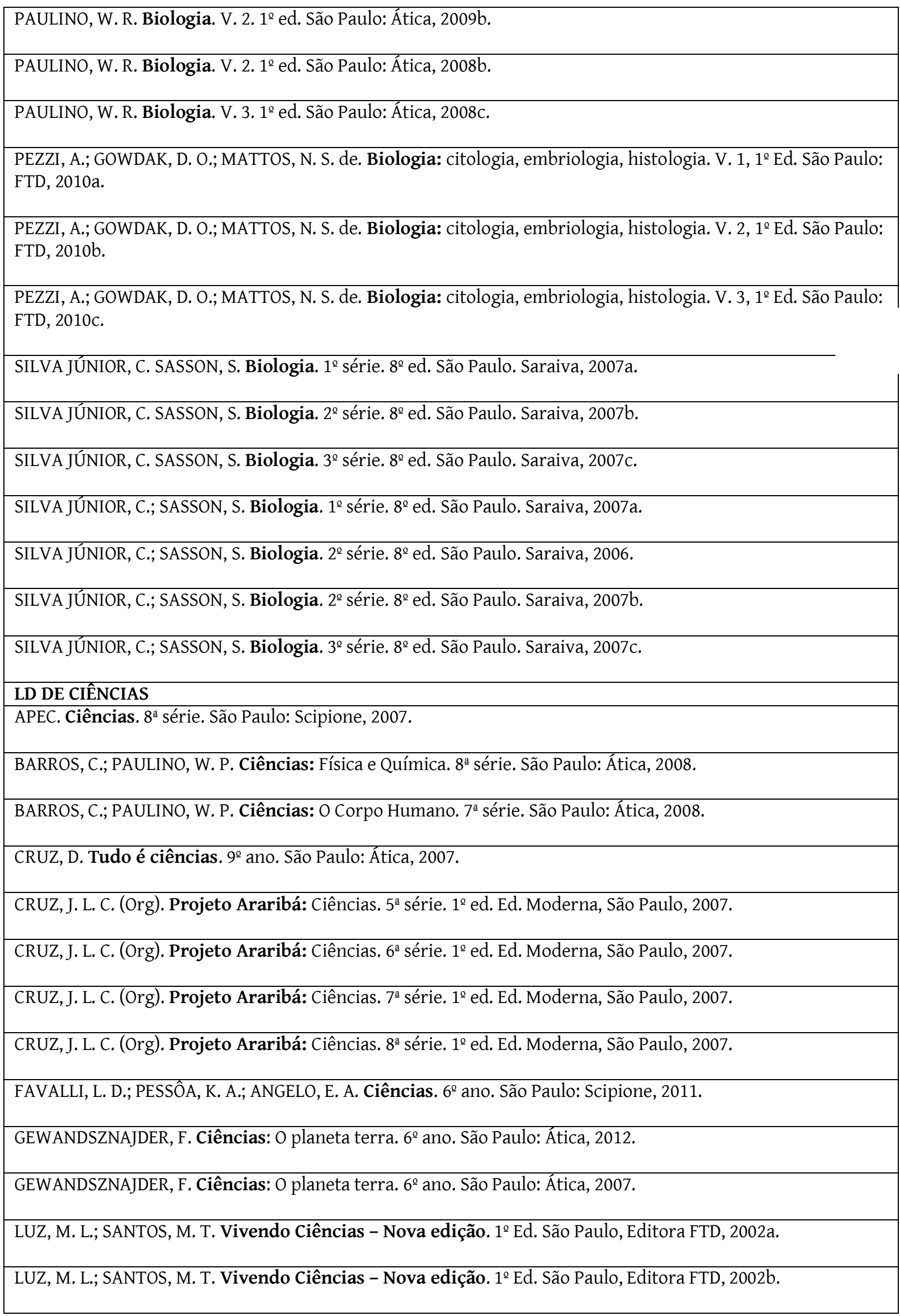


Corpo e infecções sexualmente transmissíveis: análise dos conteúdos nos livros didáticos de ciências e biologia

LUZ, M. L.; SANTOS, M. T. Vivendo Ciências - Nova edição. 1ํㅡㄹ. São Paulo, Editora FTD, 2002c.

NAHAS, T. R.; SANCHES, A. K.; CAMACHO, C. S. E. G. Decifrando a natureza. $7^{\circ}$ ano. São Paulo: Ed. Nacional, 2010.

PORTO, D. P.; MATTOS, N. S. Ciências. 6ª série. São Paulo: Scipione, 2005.

TRIVELLATO, J. et al. Ciências Natureza e Cotidiano: criatividade, pesquisa, conhecimento. $5^{\mathrm{a}}$ série. São Paulo: FTD, 2004.

TRIVELLATO, J. et al. Ciências Natureza e Cotidiano: criatividade, pesquisa, conhecimento. $6^{\mathrm{a}}$ série. São Paulo: FTD, 2004.

TRIVELLATO, J. et al. Ciências Natureza e Cotidiano: criatividade, pesquisa, conhecimento. $7^{\text {a }}$ série. São Paulo: FTD, 2004.

TRIVELLATO, J. et al. Ciências Natureza e Cotidiano: criatividade, pesquisa, conhecimento. $8^{\mathrm{a}}$ série. São Paulo: FTD, 2004.

TRIVELLATO, J. et al. Ciências, Natureza e Cotidiano: criatividade, pesquisa, conhecimento. $6^{\mathrm{a}}$ ano. São Paulo: FTD, 2009.

TRIVELLATO, J. et al. Ciências, Natureza e Cotidiano: criatividade, pesquisa, conhecimento. $7^{\mathrm{a}}$ série- $8^{\circ}$ ano. São Paulo: FTD, 2006.

\section{(cc) EY}

Este trabalho está licenciado com uma Licença Creative Commons - Atribuição 4.0 Internacional. 